\title{
RESULT GENERATION SYSTEM FOR CBGS SCHEME IN EDUCATIONAL ORGANIZATION
}

\author{
Jay Bhatt ${ }^{1}$, Raunaq Jain ${ }^{2}$, Sanket Kadge ${ }^{3}$, Priya Parate ${ }^{4}$ \\ ${ }^{1}$ Student, Computer Department, Rajiv Gandhi Institue of Technology, Maharashtra, India \\ ${ }^{2}$ Student, Computer Department, Rajiv Gandhi Institue of Technology, Maharashtra, India \\ ${ }^{3}$ Student, Computer Department, Rajiv Gandhi Institue of Technology, Maharashtra, India \\ ${ }^{4}$ Assistant Professor, Computer Department, Rajiv Gandhi Institue of Technology, Maharashtra, India
}

\begin{abstract}
The aim of our project is to automate the result generation system. We will try to implement the rules as per University norms according to the CBGS system. The necessity of this system is to ease the process of result generation and once the data is fed in the system, could be used to calculate the result and generate it in the desired format. We can analyze this data and generate various reports needed using some data mining techniques. The objective is to generate result that will be semester wise for each student. Analyzing these reports would give various parameters such as students passing or failing, semester wise as well as subject wise. The software will be accessible only to authorized users so that security could be maintained.
\end{abstract}

Key Words: CBGS System

\section{INTRODUCTION}

Result Generation is an important part of every university. It is a tedious process of fetching marks and then calculating them according to the prescribed syllabus. Automating the result generation of any university makes the job of colleges as well as people related to it a bit easy. Students are also able to get their result at the earliest. The existing system generated results based on the rules of the older system. But from the academic year 2012 the University of Mumbai introduced the most renowned credit based grading system (CBGS), which had an altogether new rules for which there was a need to develop system. Every college requires such a system that facilitates faster generation of results with minimal errors. The complexities in calculating each and every students result according to prescribed scheme is very crucial. It is very difficult to implement the various conditions prescribed by the university as the gracing rules are very complex and even to convert marks into equivalent cgpa is difficult considering the marks along with the grades. The Credit based grading system (CBGS) is introduced recently. The key component for this project would be feeding marks of students into the database and calculating the result in grade format. The final result of this project would be an automated result generation system wherein the exam cell head will need to input the marks of the students and result will be generated according to the prescribed scheme and syllabus of University.

\subsection{Literature Survey}

The present paper[1], is developed using php. The existing systems had their own disadvantages as they could be tampered with and once the mark sheets were lost, it was difficult to generate new ones. Though PDF generation of result was possible, there were some alignment issues while printing the result. This research paper[2], examined the inadequacies involved in the manual method of compiling students' result in secondary schools. In this work, a computer software application was developed to facilitate the automated processing of the results. The software was developed using PHP programming language and MYSQL.

\subsection{Existing System}

The existing system which is present for calculating the result of students is based on the previous scheme prescribed by the University. The result of the students contained only their marks along with the percentage and whether they have passed or failed. There were no credits assigned to any subject. But after the University started with the CBGS scheme, there was a need to calculate the result of all students in a new format that is very complex. Like, there were problems when the marks were entered of each student subject wise with corresponding heads. Various types of report generation were done manually which was not present in the system. For e.g. if one needed a list of students scoring 65+ marks in a particular subject in that academic year then it was done manually which was a time taking processes. Teachers found it difficult to fill in the self-appraisal form which again needed calculations which was indeed done manually.

\subsection{Proposed System}

System is based on CBGS scheme. There was an extra task of calculating and assigning the credits and grades according to the particular subject which was prescribed by the University. Student marks entry is in a convenient manner. Database is stored in MySQ1, with the restricted number of users allowed to handle software. This database is highly scalable as $\mathrm{N}$ number of student entries can be made without 
disturbing the performance of the system. It is also good for performing complex queries which may be later used for data mining purposes. As MySQ1 is used, it is highly reliable as it is good to execute concurrent execution of process and performance is high. A new staff using the software will take no time to get familiar with the system as the system is not very much complex, it is user friendly.

\section{WORKFLOW}

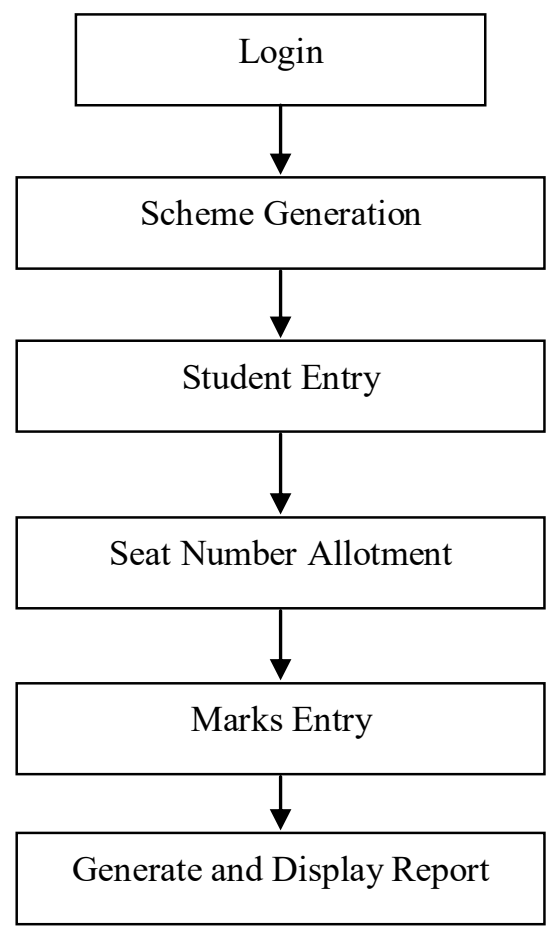

Fig 1. Workflow

\section{EXPERIMANTATION AND SIMULATION STUDY}

\subsection{Schema Creation In Database}

Here we will be creating databases for semester wise data with the fields containing the subject heads, the credits which they have and more. Also there would be a Student Database containing information about the students like student id, student name, caste, gender, etc.

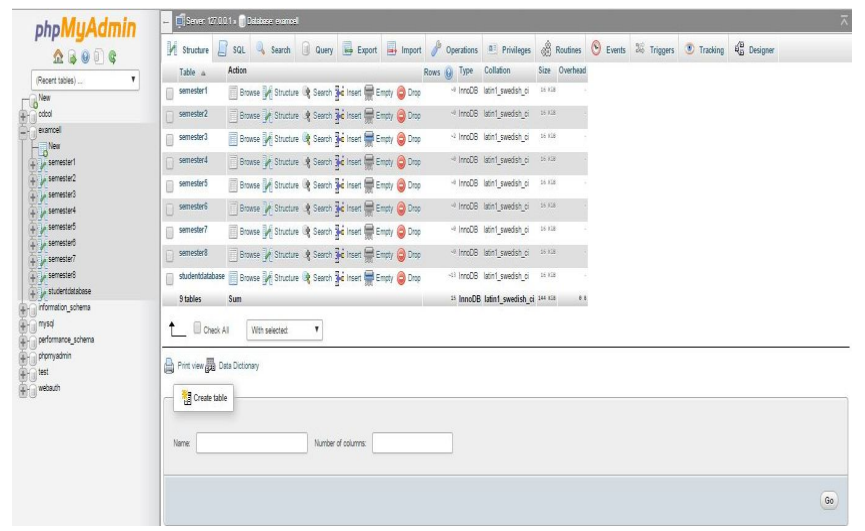

Fig 2. Scheme Creation

\section{Student Entry}

Once all the databases have been created, the list of students eligible in the particular semester will be entered. Considering the students who have a $\mathrm{KT}$ in the exam will again have to be entered in the semester database but with a different year head.

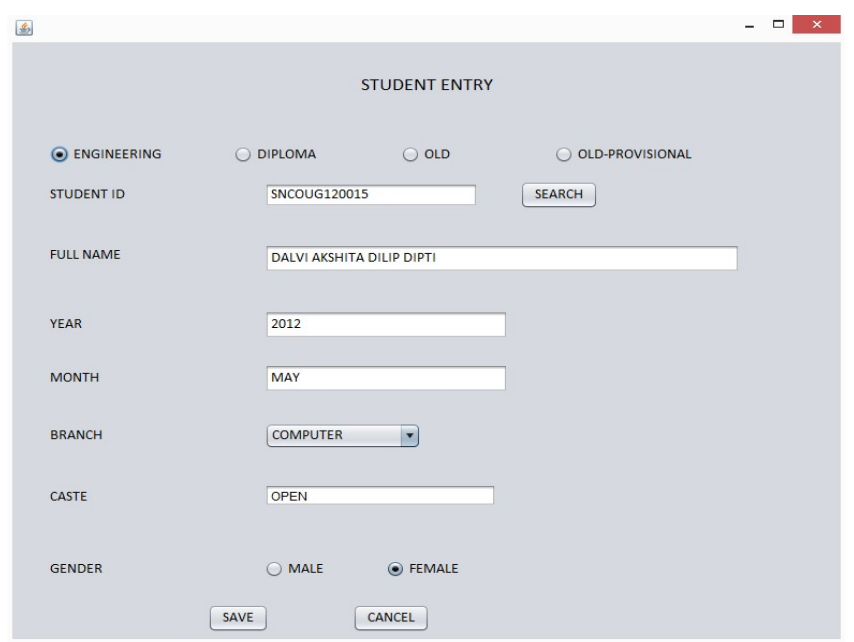

Fig 3. Students Entry

\subsection{Seat Number Allotment}

Now since all the entries have been made in the databases, students will be sorted according to their surnames or mothers name as per the rules of the college. As soon as the sorting is done seat numbers will be allotted accordingly. For e.g. if a student is in $4^{\text {th }}$ semester his seat number will be starting from number 4 only.

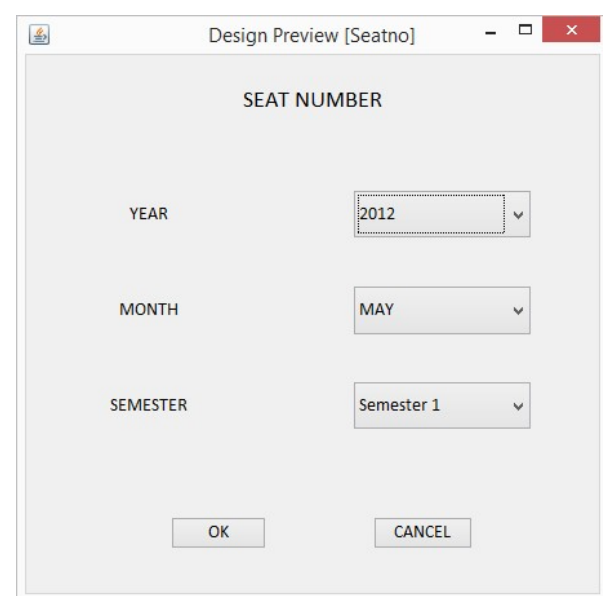

Fig 4. Seat Number Allotment

Marks entry

This module displays GUI to enter the marks of each student subject wise into the system. The user would first need to select the branch \& then the semester and the year e.g. SEM-VII/DEC-2016.After that the user would need to select the subject for which he/she wants to enter the marks. The list of eligible candidates appearing for that Semester would automatically appear in the GUI sheet. The user can then fill up the marks accordingly. 


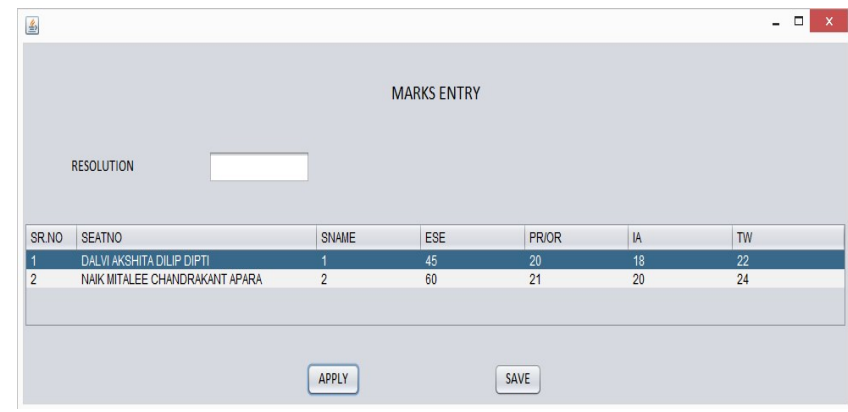

Fig 5. Marks Entry

Calculation

Since the marks have been feeded in the database, these marks would be used for further computation. All the required calculations to generate the result would be calculated here.

\section{Calculations of GPA \& SGPA}

\section{Grade Point Average (SGPA Calculation)}

Semester Grade point Average (SGPA):- It is the summation of product of Credit Points and Grade Points divided by the summation of Credits of all Courses.

$$
\text { SGPA }=\quad \sum \text { CG } \quad \text { For a semester }
$$

\section{$\sum \mathrm{C}$}

Where $\mathrm{G}$ is grade and $\mathrm{C}$ is credit for Course

Cumulative Grade Point Average (CGPA) for the Entire Course

$$
\sum \mathrm{CG}
$$

$\begin{array}{cl}\text { CGPA }= & \begin{array}{l}\text { For all semesters taken } \\ \text { together }\end{array} \\ \sum \mathrm{C} & \end{array}$

\section{PERFORMANCE GRADING}

Table 1. Grading table

\begin{tabular}{|l|l|l|l|}
\hline GRADE & MARKS & $\begin{array}{l}\text { GRADE } \\
\text { POINTS }\end{array}$ & REMARKS \\
\hline O & 80.00 and above & 10 & Outstanding \\
\hline A & $75.00-79.99$ & 9 & Excellent \\
\hline B & $70.00-74.99$ & 8 & Very Good \\
\hline C & $60.00-69.99$ & 7 & Good \\
\hline D & $50.00-59.99$ & 6 & Fair \\
\hline E & $45.00-49.99$ & 5 & Average \\
\hline P & $40.00-44.99$ & 4 & Pass \\
\hline F & Less than 40.00 & 0 & Fail \\
\hline
\end{tabular}

\section{Result Generation}

In this module the result will be generated into the required format for the future use of the college that can be used for auditing. The report will be in excel format or in PDF format as per the requirement.

\section{FUTURE WORK}

The records of the students are stored in MySQL. The data can be fetched from MySQL to excel sheets if needed. Forecasting is more easier in excel sheets. By using data mining technique i.e. linear Regression which will help in forecasting students result. We can find out some particular features for e.g. predict the toughness of subject and accordingly divide the subjects in tough category and scoring category. Also for analytical study various graphs, histograms can be generated accordingly. Report generations are one click away. Various reports of students based on the college requirements can be generated very easily. Suppose the responsible person, who needs a particular kind of report, for example list of students having a KT in academic year 2015-16 in OOPM can get it easily and need not search it manually.

\section{CONCLUSIONS}

In this proposed system, a system is developed which will ease the use of the exam cell department in doing their work and it will also indirectly help students to avail their results at the earliest. This is done by making the GUI very userfriendly to use and also putting complex conditions in a simple way which would increase the performance of the system, thus automating the system as much as possible. The system also takes into account the list of students having a KT in that year.Though the redundancy is present, but due to an efficient database being used, it is scalable and performance is not reduced.

\section{ACKNOWLEDGEMENT}

We would like to thank our guide, Prof. Priya Parate, Department of Computer Engineering, for all the advice, encouragement and constant support that she has given throughout our project work. We would also like to thank Prof. D.P.Kapse and Prof. Vaidehi Takalikar for their support and valuable suggestion has made our project achievable.

\section{REFERENCES}

[1] Srushti Shimpi, Sanket Mandare, Tyagraj Sonawane, Aman Trivedi, K. T. V. Reddy,"PDF Marksheet Generator", Proceedings of I.J. Information Technology and Computer Science, 2014, vol-11,pp 36- 41.

[2] Ezenma A. Añulika, Emmanuel Bala, Choji D. Nyap," Design and Implementation of Result Processing System for Public Secondary Schools in Nigeria", Proceedings of International Journal of Computer and Information Technology (ISSN: 2279 - 0764), Vol. 03 - Issue 01, January 2014. Website http://www.slideshare.net/shivanigogia/student-resultmanagement3 